\title{
Double Amino Functionalized Ag Nanoparticles as SERS Tags in Raman Diagnostic
}

\author{
Simona Cîntă Pînzaru, ${ }^{\text {a,* }}$ Alexandra Falamaş, ${ }^{a}$ Cristina Dehelean, ${ }^{b}$ \\ Cristian Morari, ${ }^{c}$ and Monica Venter ${ }^{d}$ \\ ${ }^{a}$ Department of Biomedical Physics, Theoretics and Molecular Spectroscopy, Babeş-Bolyai University, \\ Kogălniceanu 1, RO-400084 Cluj-Napoca, România \\ ${ }^{\mathrm{b}}$ Victor Babeş University of Medicine and Pharmacy, Faculty of Pharmacy, \\ Eftimie Murgu Square 2, RO- 300041, Timişoara, România \\ ${ }^{\mathrm{c}}$ INCDTIM Cluj-Napoca, Donath Str. 65-103, 400239, Cluj-Napoca, Romania \\ ${ }^{\mathrm{d}}$ Babeş-Bolyai University, Faculty of Chemistry and Chemical Engineering, \\ Arany Janos 11, RO-400028 Cluj-Napoca, România \\ RECEIVED MARCH 1, 2012; REVISED FEBRUARY 28, 2013; ACCEPTED MAY 17, 2013

\begin{abstract}
Surface enhanced Raman scattering (SERS) effect is currently exploited as the basis of a new type of optical labels for in vivo investigation of the tissues, especially for early medical diagnostic. Silver colloidal nanoparticles decorated with chemisorbed cresyl violet molecular species could act as hybrid SERS labels. Their Raman scattering properties have been characterized here using different SERS techniques, and probing different excitation wavelengths, even in the near infrared. Obtaining FT-SERS signal of cresyl violet is of particular importance for applying FT-Raman spectroscopy to the tissues or cells, in providing sensitive information in the close vicinity of the SERS label incubated into the biological sample. Furthermore, upon chemisorption on the silver nanoparticles, cresyl violet molecular orientation provided both amino functional groups free of interaction with the silver, resulting double aminofunctionalized Ag nanoparticles suitable for DNA tagging. SERS tests of melanoma induced in mouse using CV-Ag SERS label suggested the possibility to setup the tissue labeling procedure for skin cancer monitoring.(doi: 10.5562/cca2067)
\end{abstract}

Keywords: FT-SERS, SERS label, cresyl violet, amino functionalized- Ag nanoparticles

\section{INTRODUCTION}

Many recent reported chemical, biological and medical sensing applications involve different Raman and surface-enhanced Raman scattering (SERS) techniques as powerful analytical tools. ${ }^{1-3}$ Improved understanding of the mechanisms that are responsible for the effect coupled to the progresses in current technology make the use of SERS/SERRS much simpler than has been the case in the past. A critical review recently provided the latest methods for the metabolic fingerprinting using vibrational techniques as potential tools for rapid disease diagnosis, detection of dysfunction, the early intervention of therapeutic strategies, highlighting their overall conclusions that IR and Raman techniques could be successfully applied in such medical area. ${ }^{4}$ The difficulty in producing uniform, highly sensitive, and reproducible SERS substrate has limited its use in routine biosensing. Detection and discrimination of specimens in complex biological media are also a necessity, together with reproducible results, cost and time effectiveness, and ease of use under most conditions. Due to its unique ability to provide ultrasensitive detection limits, SERS has been used to detect molecular modifications involved in disease, such as cancer, ${ }^{3,5}$ diabetes, ${ }^{6}$ etc.

As recently summarized, there are two main SERS configurations that have been used in biosensing. ${ }^{7}$ An intrinsic procedure supposes that the analyte can be directly applied to the nanostructured surfaces and the inherent Raman spectrum of the biomolecule directly measured to identify the specimen. The extrinsic route applied the specimen immobilization onto the noble metal nanoparticles using a Raman reporter molecule to generate a signal for detection. For example, a gold nanoparticle may be used as the SERS-active substrate to which a Raman reporter molecule is immobilized. By coating this structure with another layer of dielectrics

\footnotetext{
* Author to whom correspondence should be addressed. (E-mail: simona.cinta@phys.ubbcluj.ro)
} 
such as $\mathrm{SiO}_{2}, \mathrm{TiO}_{2}$, or a polymer, a core-shell complex is formed in which the outer-shell may be decorated with capture molecules such as antibodies, peptides or small molecules. When conjugated with biomolecular targeting ligands, these shell-coated nanoparticles can be used to target malignant tumors with high specificity and affinity. Thus, specimens may be captured and detected via a sandwich structure. This extrinsic SERS detection method has been successfully used for in vivo tumor targeting ${ }^{2}$ or cancer cells imaging. ${ }^{8-10}$

A special category of nanoparticles has been largely developed featuring cationic amino acid-based side chains aiming the biological studies. ${ }^{11,12}$ This controlled surface modification provides a tool to investigate the effect of various non-covalent interactions at the nanoparticle-DNA interface. The binding affinities of these nanoparticles towards DNA were determined using fluorescence, exhibiting more than threefold modulation in binding a 37-mer DNA strand. The secondary structure of the DNA strand was distorted upon nanoparticle binding, with the extent of distortion dependent on the structure of amino acid side chain aspect that indicate that amino acid type is important. The affinity of the nanoparticle for the DNA can be regulated by external agents, though stability of the complex is observed at relatively high ionic strengths, DNA targeting being a new direction for toxicogenomics and toxicoproteomics. A proper method of evaluation could obviously increase the medical application area.

Surface subcutaneous injection of silver particles mixed with proper compounds and vehicle can form under UVB exposure nanostructures. Performing SERS measurements on skin, Ghosh et al. ${ }^{13}$ evaluated the skin damage on a faster procedure.

Controlling the size and shape of the nanoparticles it is possible to tune the plasmon resonance toward infrared range and consequently, to use NIR-SERS spectroscopic methods. At the size range of 10 to 100 $\mathrm{nm}$ diameter, the nanoparticles have large surface areas for conjugating to multiple diagnostic (e.g., optical, radioisotopic or magnetic) and therapeutic (e.g., anticancer) agents, allowing spectroscopic detection and identification of single molecules under ambient conditions. Taking the example cited above, ${ }^{2}$ it was shown that the thiol-pegylated gold nanoparticles become so stable that their SERS signal did not change under very harsh conditions including strong acids, concentrated salts, strong bases and organic solvents (dimethylsulfoxide, methanol and ethanol) and the thiol compounds do not displace the adsorbed reporter molecule such as crystal violet, Nile blue, basic fuchsin, malachite green and cresyl violet. For tissue and in vivo applications it is assumed that these reporter dyes are strongly adsorbed and the electrostatic interactions contribute to the process, due to the molecular positive charge and $\pi$-elec- tron delocalization. In contrast, organic dyes with negative charges such as sodium fluorescein gave only weak and unstable SERS signals on the citrate-stabi-lized nanoparticles (also negatively charged).

Different cresyl violet (CV) molecular species have been recently involved in many biomedical applications using SERS, owing to their large SERS efficiency, as previously described. ${ }^{14} \mathrm{CV}$ was chosen as Raman label, either conjugated to biotin for cellular enzymatic detection or adsorbed on silver nanoparticles for SERS, aiming to detect proteins. ${ }^{1}$ Among other dye reporters, Vo-Dinh et al. ${ }^{1}$ used cresyl fast violet (CFV), cresyl violet acetate (CVA), and the silver colloidal nanoparticles prepared according to the method reported by Leopold and Lendl. ${ }^{15}$ with an average diameter of about 23 nm (as examined by TEM measurements). SERS images and spectra of Chinese hamster ovary $\mathrm{CHO}$ cells incubated with CV-labeled silver colloidal nanoparticles have been investigated. The SERS image was acquired at a SERS intense band at $596 \mathrm{~cm}^{-1}$ characteristic for cresyl violet, using a $632.8 \mathrm{~nm} \mathrm{He}-\mathrm{Ne}$ laser for excitation. The SERS signal has not been obtained from any type of the cells used. Depending on the experimental conditions and the time allowed for the passive uptake of the labeled nanoparticles by the cells, the SERS signal was non-homogeneously distributed over the cells that allowed imaging. ${ }^{1}$ Beyond the fingerprint band at $596 \mathrm{~cm}^{-1}$, other weak bands of cresyl violet at 1196 and $1644 \mathrm{~cm}^{-1}$ have been observed in the SERS spectrum. The cells labeling procedure involved the use of phosphate buffer solution which contained $\mathrm{Cl}^{-}$ions, able to induce nanoparticles aggregation. However, any band attributable to the $\mathrm{Ag}-\mathrm{Cl}$ or $\mathrm{Ag}-\mathrm{CV}$ bonds has not been obtained, rising questions about the cresyl violet chemisorption process, the functional groups involved in adsorption and consequently, the label stability and efficiency.

Hence we felt it pertinent to investigate here the availability of the amino functional groups of the cresyl violet molecule for Ag adsorption and/or for DNA targeting. The further aim of the present work was to determine whether SERS spectra can be acquired from cresyl violet labeled Ag nanoparticles using FT-SERS with the near infrared $1064 \mathrm{~nm}$ laser line, less aggressive for tissues investigation.

Aiming to describe the adsorption geometry of the CV-labeled Ag nanoparticles, SERS studies undertaken using different experimental conditions are reported and compared in the present work. The information about the label stability which does not suffer from photobleaching, and can be excited at any excitation wavelength, even in the near infrared, is further used to test the specific Raman signatures of the reporters buried in animal tissue to probe the melanoma monitoring using FT-SERS. 


\section{EXPERIMENTAL}

\section{Chemicals and Materials}

The cresyl violet perchlorate was purchased from Sigma-Aldrich as polycrystalline dark powder of analytical grade purity.

The silver colloid was prepared according to a method reported by Lee and Meisel. ${ }^{16} 50 \mathrm{ml}$ of a $10^{-3} \mathrm{~mol} \mathrm{~L}^{-1} \mathrm{AgNO}_{3}$ aqueous solution was heated to boiling and then $1 \mathrm{ml}$ of a $1 \%$ trisodium citrate $\left(\mathrm{C}_{6} \mathrm{H}_{5} \mathrm{O}_{7} \mathrm{Na}_{3}\right)$ solution was added. The mixture was kept boiling for 1 hour and then was allowed to cool down. The resultant colloidal mixture was of dark grey colour.

$\mathrm{CV} 10^{-3} \mathrm{~mol} \mathrm{~L}^{-1}$ aqueous solution has been prepared using triple distilled water. Further diluted solutions have been obtained and used to prepare the SERS samples. Small amounts of $\mathrm{CV}$ aqueous solution dropped on $1 \mathrm{ml} \mathrm{Ag}$ colloid allowed obtaining final SERS concentrations from micromole to $10 \mathrm{pmol} \mathrm{L}^{-1}$.

Tissue samples were isolated from healthy and melanoma induced in Sprague Dowley rat specimens from the Biobase of the University of Medicine and Pharmacy "Victor Babes", Timisoara (UMFT). Ethical approval from the Bioethical Committee, UMFT, has been obtained in order to study sample tissues. From a normal skin to a pathologic aspect, the histological evaluation along 10 weeks of 10 minutes daily UV exposure showed a disposition of epithelial zone with cubulous aspects, conjunctive tissue destruction, maintenance of skin anexes. A second step showed hiperkeratosis with an inflammatory infiltration. Further, abundant surface lesions with hyperkeratosis tendency, lesions in basal layer of epidermis, desmoplasic dermal reaction and increasing of collagen fibers have been observed. Finally, subepidermal densification was noticed together with abundant basal layer cells, increasing of blood tissues in dermis and the absence of keratinisation desmoplasic reaction, confirming the melanoma.

$\mathrm{CV}$-labeled Ag nanoparticles have been injected in extremely small dosages into subcutaneous sites in live animals. Three freshly collected thin skin tissues (dermis-epidermis) of about $5 \times 5 \mathrm{~mm}^{2}$ incubated for 4 hours with SERS label solution $\left(10^{-5} \mathrm{~mol} \mathrm{~L}^{-1}\right)$ have been isolated in formalin solution. Each sample was further cross sectioned and direct deposited on the microscope slides for spectral data acquisition.

Microscopic examination using $10 \times$ or $50 \times$ objectives has been performed before and after the near infrared laser exposure in order to monitor the possible morphological changes induced by the laser beam on the focused point. The optical image of the tissue was found unchanged upon laser exposure. A video-camera assisted the tissue behavior under measurement.

\section{Instrumentation}

UV-VIS spectra have been recorded using a Jasco spectrometer V-530 model equipped with a grating monochromator with 1200 lines $/ \mathrm{mm}$. The spectral domain goes from 190-1100 nm depending on the used light source. For the UV domain (190-350 nm) it uses a deuterium lamp, while for the VIS-NIR region (330-1100 nm), a tungsten lamp.

SERS spectra of $\mathrm{CV}$ were collected using a Raman micro-spectrometer (HORIBA Jobin Yvon, model LabRam), equipped with 1800 grooves/mm holographic gratings. For the excitation, the $488 \mathrm{~nm}$ line from an Arion laser or the $647 \mathrm{~nm}$ line from a Kr-ion laser was employed, respectively. The spectra were collected in the backscattering geometry using a microscope equipped with an Olympus LMPlanFL 50x or 10x objective with a spectral resolution of $2 \mathrm{~cm}^{-1}$. The spectrally dispersed Raman signal was detected with a Peltier-cooled CCD detector, with 16 bit dynamic range, size $1024 \times 256$ pixel. The spectral data were analyzed using the LabSpec 4.08 and Origin 6.1 software.

FT-Raman/FT-SERS spectra have been recorded using an Equinox 55 Bruker spectrometer with an integrated FRA 106 S Raman module fiber optic coupled with a Ramanscope II micro-Raman setup. A Nd:YAG laser operating at $1064 \mathrm{~nm}$ line with an output laser power of $350 \mathrm{~mW}$ was employed for excitation and a Ge detector operating at liquid nitrogen temperature, for detection.

The spectral resolution was $4 \mathrm{~cm}^{-1}$ and different numbers of scans ranging from 50 to 350 were accumulated for optimal acquisition data for each sample.

\section{RESULTS AND DISCUSSION}

Cresyl violet perchlorate, also known as oxazine 9 perchlorate (molecular weight $361.74 \mathrm{~g} \mathrm{~mol}^{-1}$; melting point $331-333^{\circ} \mathrm{C}$ ), presents a planar molecular structure with the exception of the amino functional groups (Figure 1a). In spite of its large use for biomedical applications, a complete vibrational characterization of the adsorbed CV was missing in the field. To the best of our knowledge only one vibrational approach has been earlier reported by Vogel et al. ${ }^{17}$ and this was performed using DFT calculations achieved with the Gaussian 94 software package. From the SERS spectra of cresyl violet perchlorate on $\mathrm{Ag}$ island films ${ }^{17}$ collected in the $300-1800 \mathrm{~cm}^{-1}$ spectral range it was concluded that a physisorption process takes place and the molecular skeleton is adsorbed into a standing up orientation with respect to the Ag island film, both amino groups of the molecule being in the proximity of the metal surface. The $200-300 \mathrm{~cm}^{-1}$ range where the possible moleculemetal bonds ${ }^{18}$ could appear, was not reported.

To support the complete vibrational assignments of the $\mathrm{CV}$, density functional theory (DFT) calculations 
<smiles></smiles>

(a)

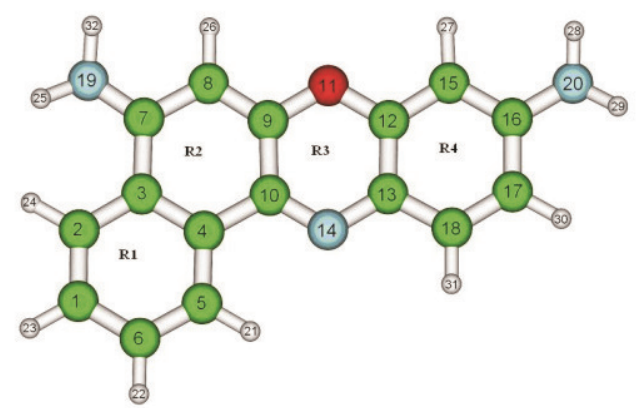

(b)

Figure 1. The schematic drawing of the cresyl violet perchlorate (a), and its optimized geometry indicating the atom numbering scheme (b). The R1 to R4 denotes the ring number employed for the vibrational modes characterization.

on cresyl violet have been conducted. Briefly, for the geometry optimizations and the vibrational wavenumbers we employed DFT calculations at the B3LYP level of theory using Gaussian 98 software package. ${ }^{19}$ For the expansion of the orbitals we used the splitting valence basis set 6-31 G(d) of Pople's group. ${ }^{20}$ All the calculations were achieved using restricted closed-shell formalism. The calculated vibrational wavenumbers were scaled using scalar factors recommended by Scot and Radom ${ }^{21}$ and by Sinha and co. ${ }^{22}$

The optimized geometry of the $\mathrm{CV}$ molecular structure at B3LYP/6-31G(d) level of theory is shown in Figure $1 \mathrm{~b}$.

The free CV molecule in aqueous solution exhibits two exocyclic nitrogen atoms which may exists in the $\mathrm{NH}$ or $\mathrm{NH}_{2}{ }^{+}$and $\mathrm{NH}_{2}$ or $\mathrm{NH}_{3}{ }^{+}$forms, respectively. According to DFT calculations which takes into account the molecular orbitals delocalized over the entire molecule, the identity of these forms does not affect the calculated frequencies. Therefore, we settled the molecule bearing double amino groups.

For an accurate description of the complex coupled vibrations occurring in the fused aromatics, the following ring numbering scheme was adopted (Figure 1): $\mathrm{R} 1$ ring: $\mathrm{C} 1-\mathrm{C} 6$; $\mathrm{R} 2$ ring $\mathrm{C} 7 \mathrm{C} 8 \mathrm{C} 9 \mathrm{C} 10 \mathrm{C} 4 \mathrm{C} 3$; $\mathrm{R} 3$ ring: $\mathrm{O} 11 \mathrm{C} 12 \mathrm{C} 13 \mathrm{~N} 14 \mathrm{C} 10 \mathrm{C} 9$ and $\mathrm{R} 4$ one C12C15C16C17C18C13.

The two exocyclic $\mathrm{NH}_{2}$ groups are denoted for simplicity as "first amine" $\mathrm{H} 25 \mathrm{~N} 19 \mathrm{H} 32$ linked to R2 and "second amine" H28N20H29, linked to R4, respectively. Due to their high anharmonicity, some of the calculated wavenumbers deviate about $10 \mathrm{~cm}^{-1}$ from the experimental values. As a curiosity, the present DFT data have been compared to those reported by Vogel et al. ${ }^{17}$ using an older Gaussian version. Most of their wavenumbers differ within $5-20 \mathrm{~cm}^{-1}$ range in the $1800-300 \mathrm{~cm}^{-1}$ reported spectral range.

UV-VIS spectrum of cresyl violet perchlorate $10^{-3} \mathrm{~mol} \mathrm{~L}^{-1}$ aqueous solution (Figure 2) presents an absorption maximum at $555 \mathrm{~nm}$, its ethanol solution at
$600 \mathrm{~nm}$, whereas the freshly prepared Ag colloid at 405 $\mathrm{nm}$. Adding a small amount of $\mathrm{CV}$ aqueous solution to the colloidal nanoparticles a new band at $584 \mathrm{~nm}$ is observed (Figure 2c). The aggregation of the Ag colloidal nanoparticles determines a new plasmonic band to appear at red-shifted wavelengths. This so-called charge transfer (CT) band (584 $\mathrm{nm}$ ) is very sensitive to the analyte concentration, because of the coverage effects on the Ag nanoparticles. Because of this, the intensity of the $405 \mathrm{~cm}^{-1}$ band decreases and we can conclude that the Ag colloidal particles aggregated in the presence of the adsorbed CV molecules. As can be seen (Figure 2), the 488 and $647 \mathrm{~nm}$ laser lines fall within the wings of the electronic absorption band of the $\mathrm{CV}$, therefore some resonance Raman contribution to the total SERS enhancement could be expected.

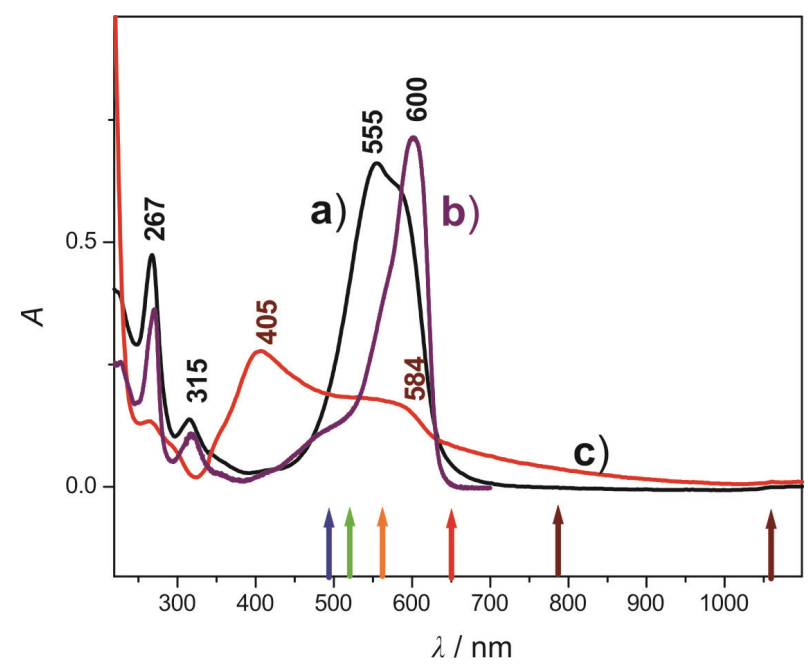

Figure 2. Absorption spectra of $\mathrm{CV} 10^{-3} \mathrm{~mol} \mathrm{~L}^{-1}$ aqueous solution (a), CV-ethanol solution (b) and $\mathrm{CV}$ dropped on $\mathrm{Ag}$ colloid $\left(19.6 \times 10^{-8} \mathrm{~mol} \mathrm{~L}^{-1}\right)(\mathrm{c})$. The bottom arrows indicate the $\mathrm{Ar}, \mathrm{Kr}, \mathrm{He}-\mathrm{Ne}, \mathrm{Nd}: \mathrm{YAG}$ or diode laser lines at 488, 514.5, $632.8,647,785$ and $1064 \mathrm{~nm}$, respectively, available for resonant or non-resonant excitation of the $(\mathrm{CV}-\mathrm{Ag})$ SERS system. 
Table 1. Selected vibrational data from the FT-Raman, FT-SERS, SERS and SERRS (cm-1) of cresyl violet molecule and their proposed assignment

\begin{tabular}{|c|c|c|c|c|c|}
\hline $\begin{array}{l}\text { Calc. wave- } \\
\text { numbers } / \mathrm{cm}^{-1}\end{array}$ & FT-Raman & $\begin{array}{l}\text { FT-SERS } \\
(1064 \mathrm{~nm})\end{array}$ & $\begin{array}{l}\text { SERS } \\
(488 \mathrm{~nm})\end{array}$ & $\begin{array}{l}\text { SERRS } \\
(647 \mathrm{~nm})\end{array}$ & Vibrational assignments \\
\hline 3116.13 & $3187 \mathrm{w}$ & $3138 \mathrm{sh}$ & - & & $v(\mathrm{CH}) \mathrm{R} 1$ \\
\hline 3075.15 & $3079 \mathrm{w}$ & $\begin{array}{l}3030,3080 \mathrm{sh} \\
2937 \mathrm{w}\end{array}$ & - & & $v(\mathrm{CH}) \mathrm{R} 1, \mathrm{R} 2, \mathrm{R} 4$ \\
\hline 1643.11 & $1643 \mathrm{~m}$ & $1642, \mathrm{w}$ & $1643, \mathrm{~s}$ & $1643, \mathrm{~m}$ & $\delta$ amine $1+\delta$ amine $2+v \mathrm{R} 4+v \mathrm{R} 2+\delta \mathrm{R} 3$ \\
\hline 1623.73 & $1622, \mathrm{w}$ & $1616 \mathrm{w}$ & $1625, \mathrm{w}$ sh & $1623, \mathrm{vw}$ & $\delta$ amine $2+\delta$ amine $1+v \mathrm{R} 4+\delta \mathrm{R} 3$ \\
\hline 1597.7795 & & $1592,1587, \mathrm{w}$ & $1592, \mathrm{~m}$ & $1590, \mathrm{vw}$ & $v_{\mathrm{as}} \mathrm{R} 1+\delta(\mathrm{CH}) \mathrm{R} 1+\delta$ amine $1+\delta$ amine 2 \\
\hline 1578.8948 & $1556, \mathrm{w}$ & $1563 \mathrm{w}$ & $1552, \mathrm{w}$ & $1557, \mathrm{w}$ & $\begin{array}{l}v \mathrm{R} 1+v \mathrm{R} 2+\delta(\mathrm{CH}) \mathrm{R} 1+\delta(\mathrm{C} 8 \mathrm{H} 26)+ \\
\delta(\mathrm{CH}) \mathrm{R} 4+v \mathrm{R} 4+\delta \text { amine } 1 \text { and } 2\end{array}$ \\
\hline 1536.9534 & & $1543, \mathrm{~m}$ & 1537, vw & & $\begin{array}{l}\delta(\mathrm{CH}) \mathrm{R} 1+v \mathrm{R} 1+\delta \text { amine } 1+\delta(\mathrm{C} 8 \mathrm{H} 26)+v \mathrm{R} 2+ \\
\delta(\mathrm{C} 17 \mathrm{H} 30)\end{array}$ \\
\hline 1523.0407 & $1529, \mathrm{~m}$ & $1529 \mathrm{sh}$ & & $1528, \mathrm{vw}$ & $\begin{array}{l}v \mathrm{R} 2+\delta(\mathrm{C} 9 \mathrm{C} 8 \mathrm{H} 26)+v \mathrm{R} 3+\delta(\mathrm{C} 16 \mathrm{C} 15 \mathrm{H} 27)+ \\
v \mathrm{R} 4+\delta \text { amine } 1+\delta \text { amine } 2\end{array}$ \\
\hline 1507.9024 & $1509, \mathrm{~s}-\mathrm{m}$ & $1510 \mathrm{sh}$ & $1505, \mathrm{~s}$ & $1511, \mathrm{vw}$ & $\begin{array}{l}\delta(\mathrm{CH}) \mathrm{R} 1+\delta \text { amine } 1+v_{\text {as }} \mathrm{R} 2+v_{\text {as }} \mathrm{R} 3+v_{\mathrm{s}} \mathrm{R} 4+ \\
\delta(\mathrm{CH}) \mathrm{R} 4+\delta \text { amine } 2\end{array}$ \\
\hline 1499.6972 & 1494, m & $1495, \mathrm{~s}$ & & & $\delta$ amine $2+\delta(\mathrm{CH}) \mathrm{R} 4+v \mathrm{R} 4+\delta(\mathrm{CH}) \mathrm{R} 2$ \\
\hline 1482.6737 & 1472 & 1487 vs & $1484, \mathrm{~s}$ & $1487, \mathrm{w}$ & $v \mathrm{R} 4+\delta(\mathrm{CH}) \mathrm{R} 4+v \mathrm{R} 4+\delta$ amine $1+\delta(\mathrm{CH}) \mathrm{R} 1$ \\
\hline 1462.0531 & 1452 & $1458 \mathrm{sh}$ & $1470, \mathrm{vw}$ & & $\begin{array}{l}\delta(\mathrm{CH}) \mathrm{R} 1+v_{\mathrm{as}} \mathrm{R} 2+v_{\mathrm{as}}(\mathrm{N} 14 \mathrm{C} 10 \mathrm{C} 4)+\delta \text { amine } 1+ \\
\delta(\mathrm{C} 17 \mathrm{H} 30)\end{array}$ \\
\hline 1453.0679 & $1447, \mathrm{~m}$ & $1434 \mathrm{~s}$ & $1456, \mathrm{~s}$ & & $\delta(\mathrm{CH}) \mathrm{R} 1+v \mathrm{R} 1+\delta(\mathrm{C} 8 \mathrm{H} 26)+\delta(\mathrm{C} 17 \mathrm{H} 30)$ \\
\hline 1424.5428 & $1427, \mathrm{~s}$ & $1423, \mathrm{~s}$ & $1429, \mathrm{w}$ & 1437, vw & $\delta(\mathrm{CH}) \mathrm{R} 1+v \mathrm{R} 2+\delta$ amine $1+\delta$ amine 2 \\
\hline 1400.479 & $1410, \mathrm{~s}$ & $1402 \mathrm{w}$ & $1409, \mathrm{w}$ & 1404, w-m & $\delta(\mathrm{CH}) \mathrm{R} 1+v_{\mathrm{as}} \mathrm{R} 2+\delta$ amine $1+\delta(\mathrm{C} 17 \mathrm{H} 30)+v \mathrm{R} 4$ \\
\hline 1384.2748 & $1383 \mathrm{~s}$ & $1385 \mathrm{sh}$, & $1379, \mathrm{~s}$ & 1383, w & $\begin{array}{l}\rho \text { amine } 1+v_{\text {as }} \mathrm{R} 2+\delta(\mathrm{CH}) \mathrm{R} 1+\delta(\mathrm{C} 8 \mathrm{H} 26)+ \\
v(\mathrm{C} 9 \mathrm{C} 10)+v_{\mathrm{s}} \mathrm{R} 3+v \mathrm{R} 4+\delta \text { amine } 2\end{array}$ \\
\hline 1353.7023 & $1378, \mathrm{~s}$ & $1376 \mathrm{~m}$ & & $1350, \mathrm{w}$ & $\begin{array}{l}\rho \text { amine } 2+\delta(\mathrm{C} 16 \mathrm{~N} 20 \mathrm{H} 28) v_{\mathrm{as}} \mathrm{R} 4+\delta(\mathrm{CH}) \mathrm{R} 1+ \\
\delta(\mathrm{C} 8 \mathrm{H} 26)\end{array}$ \\
\hline 1323.4228 & $1328, \mathrm{w}$ & 1334, w & $\begin{array}{l}1326, \mathrm{~s}, \\
\text { broaden }\end{array}$ & $1320, \mathrm{vw}$ & $\begin{array}{l}\delta(\mathrm{CH}) \mathrm{R} 1+\text { pamine } 1+\delta(\mathrm{C} 15 \mathrm{H} 27)+\delta(\mathrm{C} 8 \mathrm{H} 26)+ \\
v_{\mathrm{as}} \mathrm{R} 2+v_{\mathrm{as}} \mathrm{R} 3+v(\mathrm{C} 16 \mathrm{~N} 20)\end{array}$ \\
\hline 1293.74 & $1282, \mathrm{~m}$ & $1298, \mathrm{~m}, 1289 \mathrm{sh}$ & $1289, \mathrm{~m}$ & 1283, vw & $\delta(\mathrm{CH}) \mathrm{R} 4+\delta(\mathrm{CH}) \mathrm{R} 2+$ breathing $\mathrm{R} 2+v \mathrm{R} 1$ \\
\hline 1278.8527 & & & & $1265, \mathrm{vw}$ & $\delta(\mathrm{CH}) \mathrm{R} 1+\delta(\mathrm{CH}) \mathrm{R} 2+\delta(\mathrm{CH}) \mathrm{R} 4$ \\
\hline 1235.5244 & $1251, \mathrm{w}$ & $1246 \mathrm{w}$ & $1242, \mathrm{w}$ & $1259, \mathrm{vw}$ & $\delta(\mathrm{CH}) \mathrm{R} 4+\delta(\mathrm{CH}) \mathrm{R} 1+\delta(\mathrm{CH}) \mathrm{R} 2+\rho$ amine 2 \\
\hline 1181.3987 & $1194, \mathrm{~s}$ & 1196, vs & 1196, vs & $1183, \mathrm{~m}$ & $\begin{array}{l}\delta(\mathrm{CH}) \mathrm{R} 1+\delta(\mathrm{CH}) \mathrm{R} 2+\delta(\mathrm{CH}) \mathrm{R} 4+\rho \text { amine } 1+\rho \\
\text { amine } 2+v_{\mathrm{as}} \mathrm{R} 3\end{array}$ \\
\hline 1166.2967 & $1172, \mathrm{~m}$ & $1163 \mathrm{w}-\mathrm{m}$ & 1166, w & & $\delta(\mathrm{CH}) \mathrm{R} 1+\delta(\mathrm{CH}) \mathrm{R} 2+\delta(\mathrm{CH}) \mathrm{R} 4$ \\
\hline 1152.6935 & $1146, \mathrm{~m}$ & $1146, \mathrm{~m}-\mathrm{s}$ & $1140 \mathrm{w}$ & $1143, \mathrm{~m}$ & $\begin{array}{l}\delta(\mathrm{CH}) \mathrm{R} 1+\delta(\mathrm{CH}) \mathrm{R} 4+\rho \text { amine } 1+\rho \text { amine } 2+ \\
\delta(\mathrm{C} 8 \mathrm{H} 26)+v(\mathrm{O} 1 \mathrm{C} 12)\end{array}$ \\
\hline 1133.4601 & & & 1137, w & & $\begin{array}{l}\delta(\mathrm{CH}) \mathrm{R} 1+v(\mathrm{C} 3 \mathrm{C} 7)+\rho \text { amine } 1+\delta(\mathrm{CH}) \mathrm{R} 4+ \\
\rho \text { amine2 }\end{array}$ \\
\hline 1122.3894 & 1114, vw & $1113, \mathrm{sh}$ & 1108, w & $1113, \mathrm{vVw}$ & $\rho$ amine $1+\delta(\mathrm{CH}) \mathrm{R} 1+\mathrm{R} 1$ breathing $+\delta(\mathrm{CH}) \mathrm{R} 4$ \\
\hline 1097.5855 & & 1086, vw & & 1085, vw & $\rho$ amine $1+\delta(\mathrm{CH}) \mathrm{R} 1+\delta \mathrm{R} 1+\delta(\mathrm{C} 15 \mathrm{H} 27)$ \\
\hline 1038.4161 & 1046, vw & $1042, \mathrm{vw}$ & 1044, vw & 1040, w & $\begin{array}{l}\rho \text { amine } 1+\delta(\mathrm{C} 15 \mathrm{H} 27)+\delta(\mathrm{C} 8 \mathrm{H} 26)+\rho \text { amine } 2+ \\
\delta(\mathrm{CH}) \mathrm{R} 1+\delta \mathrm{R} 1\end{array}$ \\
\hline 1022.6457 & & $1017 \mathrm{vw}$ & 1017, w & 1004, w & $\begin{array}{l}\rho \text { amine } 1+\delta(\mathrm{C} 8 \mathrm{H} 26)+\rho(\mathrm{C} 6 \mathrm{C} 5 \mathrm{H} 21)+v(\mathrm{C} 1 \mathrm{C} 6) \\
+\delta(\mathrm{C} 2 \mathrm{H} 24)\end{array}$ \\
\hline 984.47639 & & 1000, w 987 w & 998, w & & $\rho$ amine $1+\rho$ amine $2+\delta(\mathrm{C} 18 \mathrm{H} 31)+v \mathrm{R} 2+\delta \mathrm{R} 1$ \\
\hline 940.91 & & $945, \mathrm{~m}$ & & & $\tau(\mathrm{C} 18 \mathrm{H} 31)+\delta(\mathrm{C} 17 \mathrm{H} 30)$ \\
\hline
\end{tabular}


Table 1. Selected vibrational data from the FT-Raman, FT-SERS, SERS and SERRS $\left(\mathrm{cm}^{-1}\right)$ of cresyl violet molecule and their proposed assignment (continued)

\begin{tabular}{|c|c|c|c|c|c|}
\hline 927.04 & & $925, \mathrm{vw}$ & & & $v \mathrm{R} 4+\rho(\mathrm{C} 18 \mathrm{C} 17 \mathrm{H} 31)+\delta(\mathrm{C} 15 \mathrm{H} 27)+\rho$ amine 2 \\
\hline 886.2296 & & $883, w$ & & $890, \mathrm{vw}$ & op, $\omega(\mathrm{CH}) \mathrm{R} 1$ \\
\hline 847.9406 & & $847, \mathrm{vw}$ & & & $\omega(\mathrm{CH}) \mathrm{R} 4$ \\
\hline 834.898 & $833, \mathrm{w}$ & $821, \mathrm{vw}$ & $832, \mathrm{w}$ & $834, \mathrm{w}$ & op, $\omega(\mathrm{CH}) \mathrm{R} 4+\omega(\mathrm{CH}) \mathrm{R} 2$ \\
\hline 770.0919 & & $778, \mathrm{vw}$ & $773, w$ & & $\tau(\mathrm{CH}) \mathrm{R} 1+\omega \mathrm{R} 2+\tau$ amine $1+\tau(\mathrm{CH}) \mathrm{R} 2$ \\
\hline 762.6204 & $750, \mathrm{vw}$ & $755 \mathrm{wm}$ & $754, \mathrm{~m}$ & $752, w$ & $\delta \mathrm{R} 1+\rho$ amine $1+v \mathrm{R} 4$ \\
\hline 742.7867 & $720, \mathrm{~m}$ & $737, \mathrm{w}$ & $731, \mathrm{~m}$ & $728, w$ & $\begin{array}{l}\omega(\mathrm{CH}) \mathrm{R} 1+\omega \mathrm{R} 3+\omega \mathrm{R} 4+\tau \text { amine } 1+\tau \text { amine } 2+ \\
\omega(\mathrm{CH}) \mathrm{R} 4\end{array}$ \\
\hline 686.4422 & $670, \mathrm{~m}$ & $672, \mathrm{~m}-\mathrm{s}$ & $672, \mathrm{~m}$ & $675, \mathrm{~s}$ & $\delta \mathrm{R} 1+\rho \mathrm{R} 1+\delta \mathrm{R} 3$ \\
\hline 656.9054 & & $656 \mathrm{w}$ & & $665, \mathrm{w}$ sh & $\tau \mathrm{R} 2+\tau(\mathrm{CH}) \mathrm{R} 1+\tau(\mathrm{CH}) \mathrm{R} 4$ \\
\hline 638.2401 & & $633, \mathrm{w}-\mathrm{m}$ & & $614 \mathrm{wm}$ & $\delta \mathrm{R} 4+\delta$ amine 1 \\
\hline 604.0966 & 589 , vs & $590, \mathrm{vs}$ & 590, vs & $590, \mathrm{vvs}$ & $\begin{array}{l}\text { quadrant stretch ip R3, } v \text { and } \delta(\mathrm{O} 11 \mathrm{C} 9 \mathrm{C} 12)+ \\
\delta(\mathrm{N} 14 \mathrm{C} 10 \mathrm{C} 13)+\delta(\mathrm{R} 1)+\rho(\mathrm{N} 20 \mathrm{H} 29)\end{array}$ \\
\hline 575.4848 & 576 , sh & $576 \mathrm{w}$ & $577, \mathrm{w}, \mathrm{sh}$ & 574, w sh & $\rho$ amine $1+\rho$ amine 2 \\
\hline 545.3768 & & $552, \mathrm{w}$ & $546, w$ & $548, \mathrm{w}$ & $\tau$ amine $1+\tau \mathrm{R} 1$ \\
\hline 531.5463 & & $525, \mathrm{w}$ & & $526 \mathrm{wm}$ & $\rho \mathrm{R} 4+\delta \mathrm{R} 4+\delta$ amine $2+\delta \mathrm{R} 1$ \\
\hline 492.6254 & $486, \mathrm{~m}$ & $491, \mathrm{~m}$ & $484, \mathrm{~s}$ & 493, s & $\tau$ amine $2+\tau$ amine 1 \\
\hline 473.4352 & & $467, \mathrm{~s}$ & & & $\rho \mathrm{R} 4+\rho \mathrm{R} 3+\delta \mathrm{R} 2$ \\
\hline 459.7649 & & $450, \mathrm{sh}$ & $455, \mathrm{vw}$ & $452, \mathrm{vvw}$ & $\omega \mathrm{R} 4+\tau$ amine $1+\tau$ amine 2 \\
\hline 447.914 & $438, w$ & $436, w$ & & $446, \mathrm{~m}$ & $\omega \mathrm{R} 3+\tau(\mathrm{CH}) \mathrm{R} 2+\tau(\mathrm{CH}) \mathrm{R} 4+\tau$ amine $1+\tau$ amine 2 \\
\hline 418.6858 & & $419 w$ & $422, \mathrm{~m}$ & $419, \mathrm{w}$ & $\tau \mathrm{R} 1+\tau$ amine 1 \\
\hline 347.2839 & $346, \mathrm{~m}$ & $347, \mathrm{~m}$ & & $345, \mathrm{~m}$ & $\rho \mathrm{R} 1+\delta$ amine 1 \\
\hline 285.7224 & $297, \mathrm{~m}$ & $284, \mathrm{vw}$ & - & & $\tau \mathrm{R} 4+\tau \mathrm{R} 3+\omega$ amine $1+\omega$ amine 2 \\
\hline 274.1145 & & $270, \mathrm{vw}$ & - & & $\omega$ amine 2 \\
\hline 260.9414 & $259, \mathrm{w}$ & $261, \mathrm{vw}$ & - & & $\delta \mathrm{R} 1+\delta$ amine 2 \\
\hline \multirow[t]{2}{*}{232.0616} & & $241, \mathrm{~m}$ & - & & $\tau \mathrm{R} 4+\omega \mathrm{R} 1$ \\
\hline & & $228 \mathrm{sh}$ & - & 227 vs & $\mathrm{Ag}-\mathrm{O}$ \\
\hline
\end{tabular}

Abbreviations: s- strong, m- medium, w- weak, v-very, sh- shoulder, ip- in plane, op- out of plane, $v$ - stretching, $\delta$ bending, $\tau$ - twisting, $\rho$ - rocking, $\omega$ - torsion; R1-R4 rings from Figure 1.

The surface plasmon resonance (SPR) of the aggregated Ag nanoparticles comprises all the available visible laser lines, broadening toward near infrared.

A selection of the experimental data from the FTRaman, FT-SERS, SERS and SERRS spectra obtained using different excitation laser lines are summarized in the Table 1 together with their tentative assignment, based on molecular vibrations simulations performed with the Molden software package. ${ }^{23,24}$ Theoretical Raman spectrum of the free cresyl violet molecule resembled well the FT-Raman spectrum recorded from the solid polycrystalline $\mathrm{CV}$ powder.

The perchlorate ion has been as well investigated, because it was believed that it may interfere with the SERS signal from CV. After comparing its theoretical Raman spectrum with the Raman and SERS spectra of $\mathrm{CV}$, it was concluded that its weak contribution does not affect the signal from the adsorbed CV.
The SERS spectrum of $1.21 \times 10^{-7} \mathrm{~mol} \mathrm{~L}^{-1} \mathrm{CV}$ concentration using Ag colloidal nanoparticles and 488 $\mathrm{nm}$ excitation line is presented in the Figure 3. Probing the same sample under the near infrared excitation (1064 nm), a very weak signal at $590 \mathrm{~cm}^{-1}$ could be observed. Increasing the laser power, an increased background only has been obtained. For recording the FT-SERS spectrum with a comparable signal-to-noise ratio a final concentration of $9 \times 10^{-5} \mathrm{~mol} \mathrm{~L} \mathrm{~L}^{-1}$ was needed (Figure 3).

In order to interpret the spectral data, the SERS band positions and relative intensities are compared to those from the Raman spectrum of $\mathrm{CV}$ aqueous solution obtained under non-resonant conditions (Table 1).

The changes observed on passing from Raman to SERS indicate a chemisorption process. The most intense bands in the SERS spectrum are located at 590, $1195,1456,1484,1505$ and $1643 \mathrm{~cm}^{-1}$. 


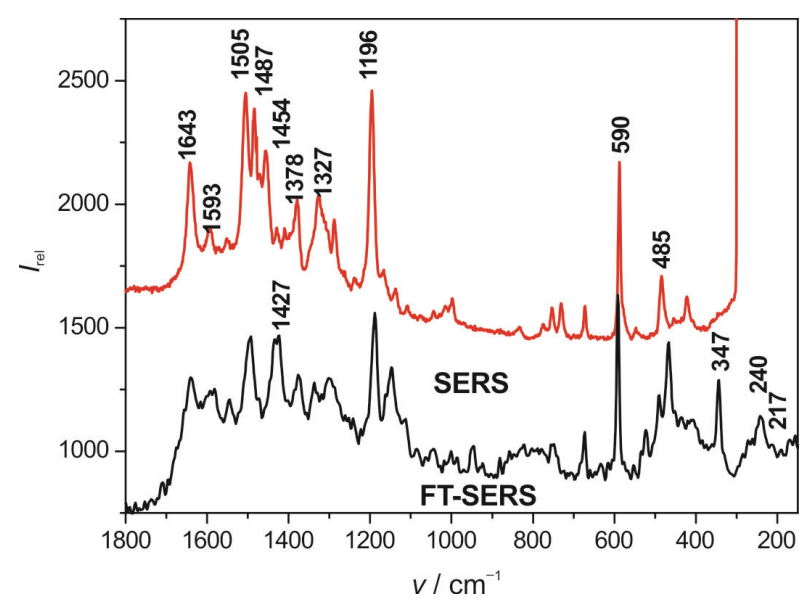

Figure 3. FT-SERS and SERS spectra of CV on Ag colloidal nanoparticles. $\mathrm{CV}$ concentration: $1.21 \times 10^{-7} \mathrm{~mol} \mathrm{~L}^{-1}$ (SERS) and $9 \times 10^{-5} \mathrm{~mol} \mathrm{~L}^{-1}$ (FT-SERS). The excitation wavelength of $1064 \mathrm{~nm}$ (FT-SERS) is not resonant with the electronic transition of the cresyl violet dye but the surface plasmon resonance of the aggregated nanoparticles is shifted toward NIR. The $488 \mathrm{~nm}$ excitation line falls into the wing of the electronic absorption band (pre-resonance).

Similar FT-SERS bands have been observed at about the same position (taking into account the spectral resolution of the different instruments and different excitation laser lines) as well as additional intense FTSERS bands at 1423, 466, 344 and $241 \mathrm{~cm}^{-1}$. The FTSERS technique allowed to record the low wavenumbers spectral range, where the $\mathrm{CV}-\mathrm{Ag}$ bond could be evidenced (Table 1).

Obtaining for the first time the FT-SERS spectrum of $\mathrm{CV}$ using $\mathrm{Ag}$ nanoparticles is of particular importance in the field, since a very limited number of molecular species exhibit NIR-SERS with Ag colloidal nanoparticles. According to the SERS theory, ${ }^{25}$ the explanation of the present results is based on the surface plasmon resonance of the aggregated nanoparticles in the presence of the adsorbate, that could reach NIR.

The SERS signal of CV attached to colloidal silver presents similarities with those reported in the literature for cresyl fast violet ${ }^{1}$ or cresyl violet perchlorate adsorbed on Ag films. ${ }^{17}$ Different results concerning SERRS signal of cresyl violet reported Jarvis et al., ${ }^{26}$ aiming to achieve an objective assessment of colloidal SERS reproducibility for quantification purpose. They reported SERRS bands at 846, 875, 930, 985, 1049, 1105, 1228, 1277 using different SERS substrate, including Lee-Meisel (SERRS). Bootstrapped correlation analysis for the log-log relationship to area under the cresyl violet SERRS band at $930 \mathrm{~cm}^{-1}$, using the polyvinylpyrrolidone (PVP) capped colloidal silver substrate raised questions regarding different SERS behavior of the molecule. None of our SERS spectra

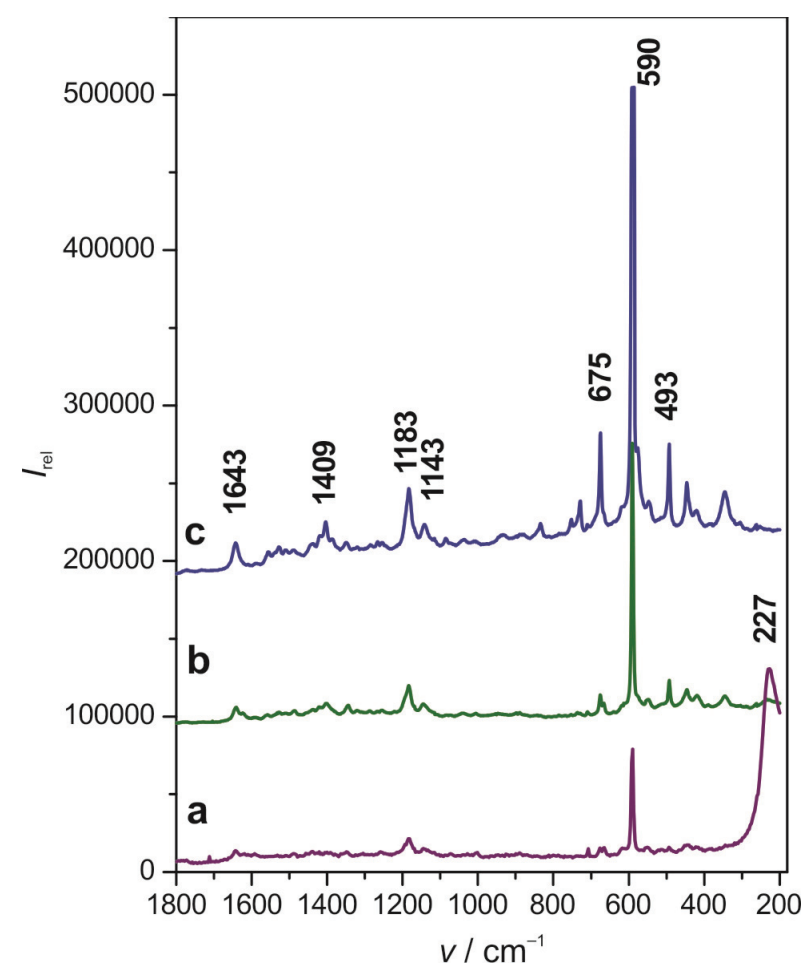

Figure 4. SERRS spectra of $\mathrm{CV}$ at different concentrations: a) $10^{-11}$, b) $10^{-10}$, c) $10^{-9} \mathrm{~mol} \mathrm{~L}^{-1}$. Excitation: $647 \mathrm{~nm}, 200 \mathrm{~mW}$.

displayed these bands. The nanostructured surface (PVP capped Ag nanoparticles according to Sun et $a{ }^{27}$ ) could be responsible for such different SERS. Therefore, we recorded the Raman spectrum of the solid PVP. The SERRS bands of cresyl violet reported by Jarvis et $a l .{ }^{26}$ were observed as strong Raman bands of the PVP.

To avoid further misinterpretation and for getting insight into the biomedical applications of this Raman dye label, a reliable SERS spectra assignment is certainly needed.

The most intense SERS band at $1196 \mathrm{~cm}^{-1}$ (also very strong in FT-SERS, Figure 3 ) can be attributed to in plane asymmetric stretching vibrations $v(\mathrm{C} 9 \mathrm{O} 11 \mathrm{C} 12)$, bending vibrations of the $\mathrm{C}-\mathrm{H}$ bonds and rocking vibrations of the amine groups. The $1456 \mathrm{~cm}^{-1}$ band is caused by in plane bending vibrations $\delta(\mathrm{C} 2 \mathrm{H} 24)+$ $\delta(\mathrm{C} 5 \mathrm{H} 21)+v(\mathrm{C} 3 \mathrm{C} 4)$ and stretching vibrations $v(\mathrm{C} 7 \mathrm{~N} 19)+v(\mathrm{C} 16 \mathrm{~N} 20)$. Another intense band in the SERS spectrum can be seen at $1643 \mathrm{~cm}^{-1}$. This signal is assigned to the in plane bending vibrations of the amines and stretching vibrations of the $\mathrm{C}-\mathrm{N}$ bonds.

The intense band at $1410 \mathrm{~cm}^{-1}$ observed in the FTRaman spectrum is seen as a weak band in SERS spectra (Table 1, Figures 3 and 4) respectively. This band was attributed to a complex mode combined from the in plane stretching and bending of the rings R1, R2, R4 and first amine deformation. 
Generally, SERS spectra have been widely used to probe the orientation of adsorbed molecules with respect to the metal surface. ${ }^{28}$ In deriving such orientation information, one makes use of the surface selection rules for roughened surface. ${ }^{28-31}$ In particular, the surface geometry of compounds which have a planar structure can be determined from the relative magnitude of the intensity of the $\mathrm{C}-\mathrm{H}$ stretching bands in their SERS spectra. A significant red shift $\left(\approx 25 \mathrm{~cm}^{-1}\right)$ and broadening of the ring bands of the flat adsorbed substituted benzene derivatives relative to the bulk spectra was observed, due to the back-donation of the electron density from the $\pi^{*}$ antibonding orbitals. In this case, a parallel orientation of the skeletal plane with respect to the nanoparticles surface could be assumed. Chemisorption through one or two amino groups or through the heteroatoms of the ring R3, supposes a tilted or perpendicular skeletal plane with respect to the surface. If so, a blue shift of the wavenumbers assigned to the involved functional groups and a change in relative intensity is expected. As it concerns the adsorption of CV cation (Figure 1a), with the molecular plane parallel to the surface, it is only the neutral $\mathrm{NH}_{2}$ group which may interact with the nanoparticle through the lone-pair electrons upon an out of plane deformation. On the other hand, the planarity of the cationic $\mathrm{NH}_{2}^{+}$group prevents any interaction with the substrate. Similarly, the endocylic nitrogen atom may not adsorb due to the planar orientation of the lone pair orbital.

Comparing the spectral data from the SERS or FTSERS with those from Raman spectra, one can observe that the vibrational modes where the amine groups are strongly involved remain unchanged. Representative is the band at $1643 \mathrm{~cm}^{-1}$ observed in Raman and SERS spectra discussed above as well as the rocking and torsion modes from lower wavenumbers. Therefore, one can conclude that the amine groups are not involved in the molecular chemisorption.

Moreover, the out of plane bendings involving C$\mathrm{H}$ groups are observed as strong SERS bands, supporting the skeleton tilted to parallel orientation of the molecule to the surface, where the amine groups are less involved into adsorption. In addition, the adsorption of cresyl violet through the exocyclic N20 atom may be sterically hindered by the hydrogen atoms.

Combining the high sensitivity of the surfaceenhanced Raman scattering (SERS) with resonance Raman (RR) conditions, CV was easily detectable at very low concentrations $\left(10^{-11} \mathrm{~mol} \mathrm{~L}^{-1}\right)$ using a red laser line $(647 \mathrm{~nm})$. Because of the large differences between the spectra recorded using the blue and red laser lines respectively, we assumed a consistent resonance contribution to the overall enhancement (SERRS) when the $\mathrm{CV}-\mathrm{Ag}$ system is excited with the $647 \mathrm{~nm}$ line. The

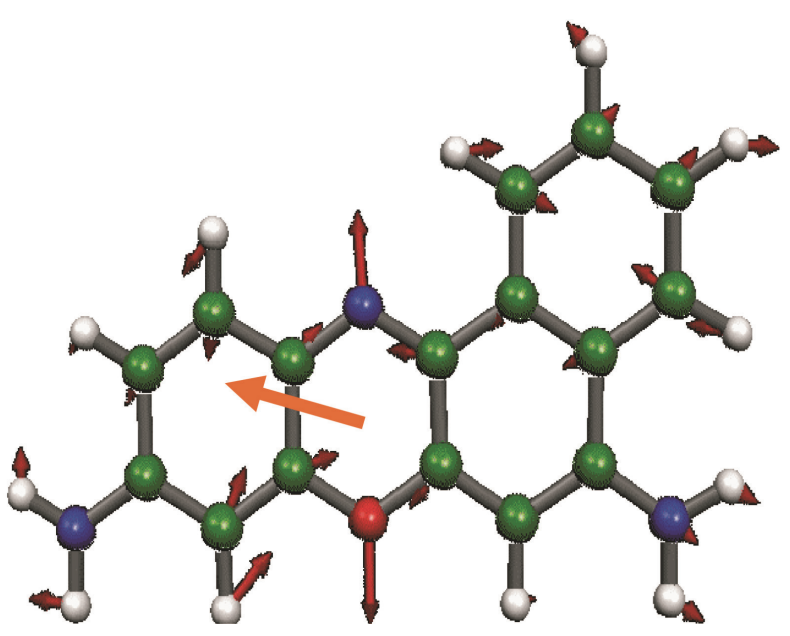

Figure 5. Vibrational mode at $590 \mathrm{~cm}^{-1}$, SERS fingerprint of $\mathrm{CV}$, presenting a strong polarizability component perpendicularly oriented to the skeletal plane (arrow).

SERRS spectra of CV at extremely low concentrations are shown in the Figure 4.

The resonant radiation excites mostly the chromophore in the adsorbed molecule, thus the vibrations in which the atoms of the chromophore group are involved, will be preponderantly enhanced. According to surface selection rules, ${ }^{28-31}$ the SERS spectra of adsorbed molecules excited with light red shifted relatively to the plasmon absorption band of the substrate will be dominated by vibrational modes having normal coordinate components perpendicular to the metal surface. $^{25}$ This condition applies for the case of $\mathrm{CV}-\mathrm{Ag}$ system excited with the $647 \mathrm{~nm}$ laser line. Which special modes will be enhanced depends on the orientation of the molecule relative to the metal surface.

Taking a closer look to the experimental data, on passing from the Raman to the SERRS wavenumbers, a small shift to lower values has been observed for several stretching modes of the skeletal plane. However, the SERRS spectra are dominated by a very intense, not shifted band at $590 \mathrm{~cm}^{-1}$, all the other SERRS bands being a few orders of magnitude intensity lower.

The characteristic fingerprint band at $590 \mathrm{~cm}^{-1}$ $(\rho=0.5)$ can approximately be described as a quadrant stretching of the central ring $v(\mathrm{C} 9 \mathrm{O} 11 \mathrm{C} 12)+$ $v(\mathrm{C} 10 \mathrm{~N} 14 \mathrm{C} 13)+v(\mathrm{C} 1 \mathrm{C} 2 \mathrm{C} 3)+v(\mathrm{C} 5 \mathrm{C} 4 \mathrm{C} 6)+$ $v(\mathrm{C} 12 \mathrm{C} 15 \mathrm{C} 16)+v(\mathrm{C} 13 \mathrm{C} 17 \mathrm{C} 18)$ and in plane rocking vibrations of the second amine $\rho(\mathrm{N} 2 \mathrm{OH} 29)$. This mode presents a strong polarizability component perpendicularly oriented to the skeletal plane, as shown in Figure 5.

The selective enhancement of this mode and the intensity distribution observed in the spectra suggests more parallel orientation of the molecular plane relative to the $\mathrm{Ag}$ nanostructured surface (polarizability orientation is perpendicular oriented to the surface, therefore, 
enhanced mode). This adsorption configuration explains the huge enhancement of the $590 \mathrm{~cm}^{-1}$ band, resulting a favorable enhancement of amine rocking mode at 1183 $\mathrm{cm}^{-1}$ as well as the out of plane amine 2 bending mode at $493 \mathrm{~cm}^{-1}$ and skeleton bending at $675 \mathrm{~cm}^{-1}$ (Figure 4, Table 1). These bands are the most representative in all the SERRS spectra, their relative intensity and position being unchanged with the change of concentration. A particular consideration would be given to the band at $227 \mathrm{~cm}^{-1}$ which exhibits a drastic intensity decrease with increasing concentration.

In the SERRS spectrum of CV $10^{-11} \mathrm{~mol} \mathrm{~L}^{-1}$ (Figure 4), the band at $227 \mathrm{~cm}^{-1}$ exhibits 1.5 times higher intensity than the fingerprint at $590 \mathrm{~cm}^{-1}$. According to literature, ${ }^{28-31}$ this band is assigned to $\mathrm{Ag}-\mathrm{O}$ bond, for oxygen-containing molecular species adsorbed through the oxygen lone pairs.

If the CV would be adsorbed to the Ag surface through the lone pair electrons of the ring nitrogen atom, involving the chromophore group resonantly excited, the $\mathrm{Ag}-\mathrm{N}$ band would have had to appear at 238 $\mathrm{cm}^{-1}$. This band was absent in our experimental spectra. We can conclude that the CV molecule is preponderantly parallel oriented or slightly tilted to the Ag surface and that there is a higher probability of chemisorption through the oxygen.

With increasing concentration, the molecular skeletal planes would completely cover the Ag surface (SERS coverage effect), resulting a totally occupation of the appropriate nanoparticles for overall enhancement. It is known that the SERS signal rises predominantly from the first adsorbed monolayer, where the electromagnetic field intensity in the close vicinity of the nanostructures is very strong, but decreases with increasing distance (field gradient enhancement). ${ }^{28-31}$ Therefore, it could be tentatively supposed that the number of molecules exhibiting SERRS signal without direct binding through the oxygen atom with the surface

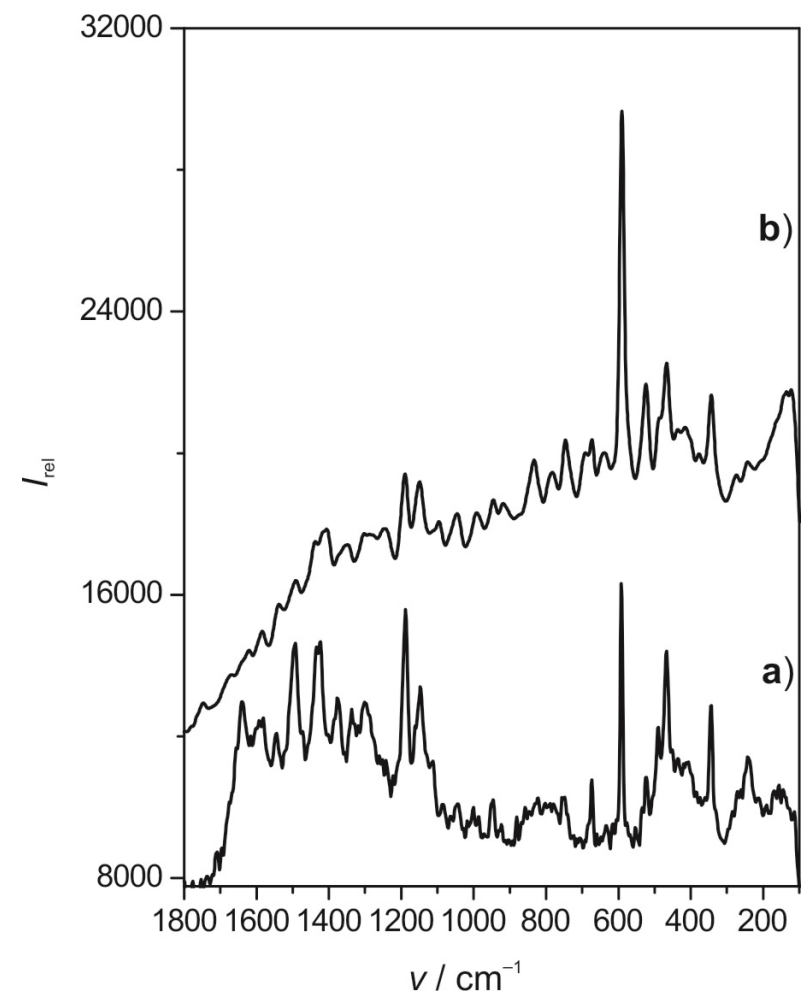

Figure 6. FT-SERS spectrum of $\mathrm{CV}$ a) in comparison with the SERS spectrum at $10^{-9} \mathrm{~mol} \mathrm{~L}^{-1}$ concentration obtained with a portable Raman instrument (b). Excitation (b): 694 nm, $5 \mathrm{~mW}$.

is significant. This supposition would explain the intensity decrease of the band at $227 \mathrm{~cm}^{-1}$ and agree with the literature.

Hildebrandt and Stockburger carried out an extensive SERRS study of rhodamine $6 \mathrm{G}$ on noble metal colloids, to explore the enhancement mechanisms involved. $^{29}$ They reported that two different types of adsorption sites on the colloid surface were responsible for the enhancement experienced: a non-specific adsorption

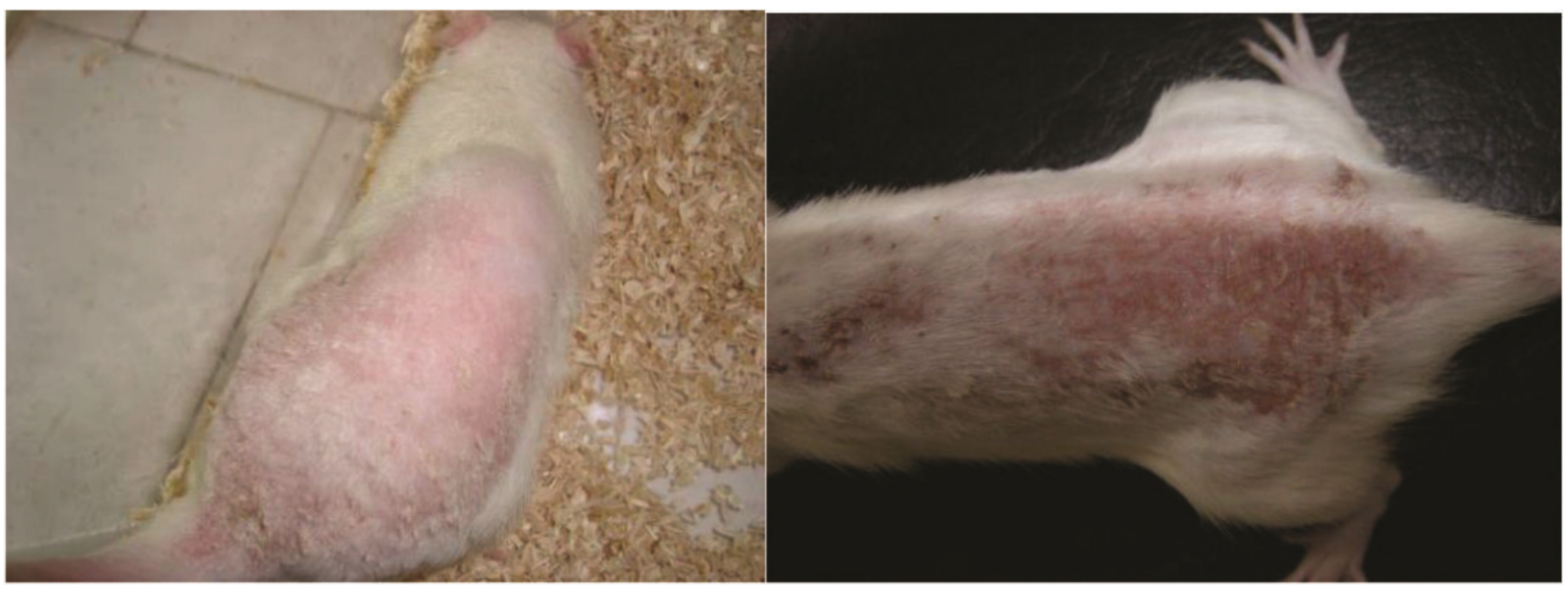

Figure 7. Skin photodamage in evolution: after 4 weeks (left), after 10 weeks (right). 
site that had a high surface coverage on the colloid surface, which resulted in an enhancement factor of 3000 and could be explained by a classical electromagnetic mechanism; and a specific adsorption site that was only activated in the presence of certain anions $\left(\mathrm{Cl}^{-}, \mathrm{I}^{-}, \mathrm{F}^{-}, \mathrm{Br}^{-}\right.$ and sulphate). This specific site had a low surface coverage (approximately three per colloidal particle); however, the authors claimed an enhancement of $10^{6}$. This enhancement was believed to be due to a charge transfer mechanism. In a further study, they concluded that charge transfer enhancement is strongly dependent upon the structural and electronic properties of the analyte. ${ }^{30}$

Cresyl violet perchlorate was easily detectable at low concentrations $\left(10^{-9} \mathrm{~mol} \mathrm{~L}^{-1}\right)$ using even a microRaman portable device (R-3000 CN from Raman Systems), as shown in the Figure 6, fact of particular importance for the further in vivo tissue diagnostic applications using portable Raman techniques.

Taking into account the overall results, based on the vibrational analysis, it can be concluded that cresyl violet is adsorbed on the Ag nanostructured surface through its chromophore group. In this adsorption process, the exocyclic $\mathrm{NH}_{2}$ groups are less involved, thus obtaining double functionalized Ag nanoparticles which are extremely important because they can bind via these functions to DNA fragments and can be used for biomedical diagnosis. ${ }^{32-35}$

In order to achieve a correct interpretation of the complex Raman signal collected from biological samples, like normal and cancerous cells or tissues which have previously been marked with functionalized $\mathrm{Ag}$ nanoparticles, understanding the adsorption mechanism of the marker molecule on the nanoparticles surface is indispensable.

Based on the above SERS results of CV on colloidal Ag nanoparticles, we tried to evaluate the possibility to investigate the $\mathrm{CV}-\mathrm{Ag}$ SERS label inoculated in complex biological samples, particularly in tissue from mice models.

Very recent, cell Raman imaging has been report$\mathrm{ed}^{36}$ using simple nanoaggregates like crystal violet or rose Bengal dye attached to gold nanoparticles, without any other capture agents like mercaptoacetic acid ${ }^{1}$ and using the $830 \mathrm{~nm}$ diode laser excitation. When introduced into the cellular cavity, Raman scattering signal of the reporter indicates the label localization into the cell compartment and simultaneously SERS in the local optical field of the decorated nanoparticles probes the chemical composition in their close vicinity.

We tested this concept for the first time in tissue, using normal and melanoma induced in different mice specimens. ${ }^{37}$ The histological evaluation from a normal skin to a pathologic aspect along 10 weeks of $10 \mathrm{~min}$ utes daily UV exposure (Figure 7) revealed several distinct steps towards malignancy as shown in the mi-
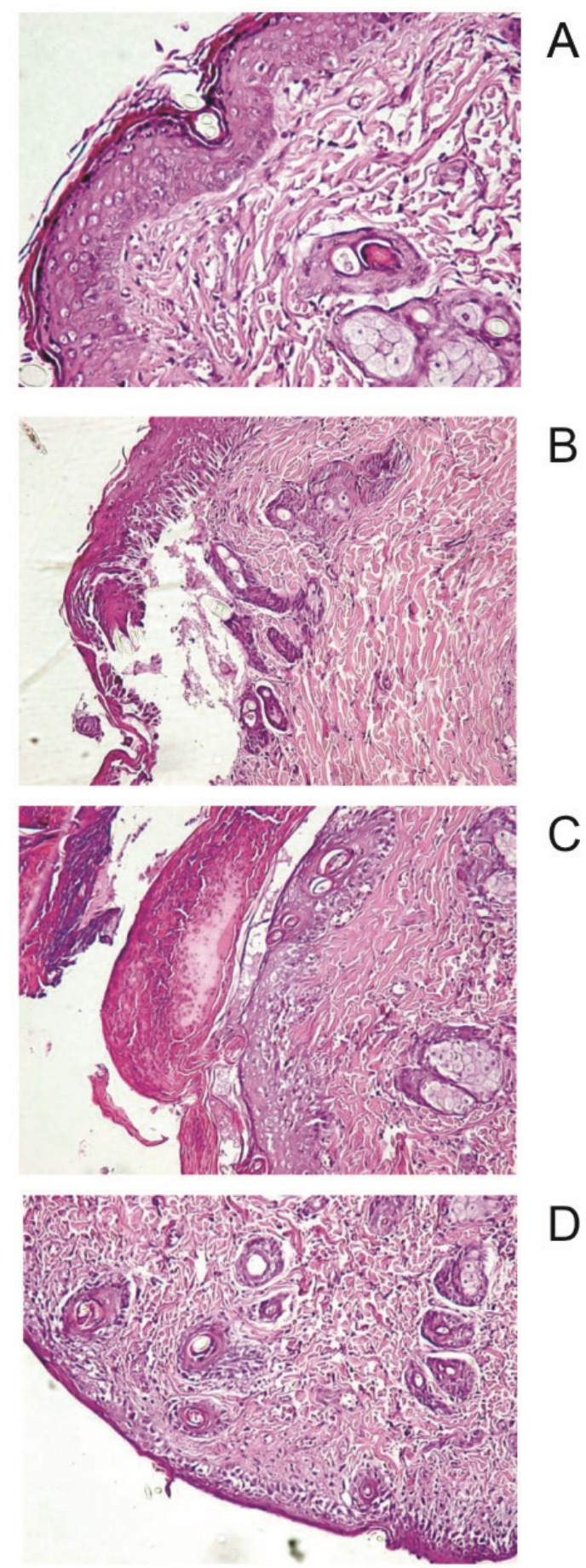

Figure 8. Optical microscopy images collected from a normal skin of Sprague Dowley rat (A) and from different stages of disease evolution: (B) disposition of epithelial zone cubulous aspects, conjunctive tissue destruction, maintenance of skin annexes; (C) hyperkeratosis with an inflammatory infiltration, abundant surface lesions with hyperkeratosis tendency, lesions in basal layer of epidermis, desmoplasic dermal reaction, increasing of collagen fibbers; (D) subepidermal densification, basal layer cells abundant, increasing of blood tissues in dermis, absence of keratinisation, desmoplasic reaction. 


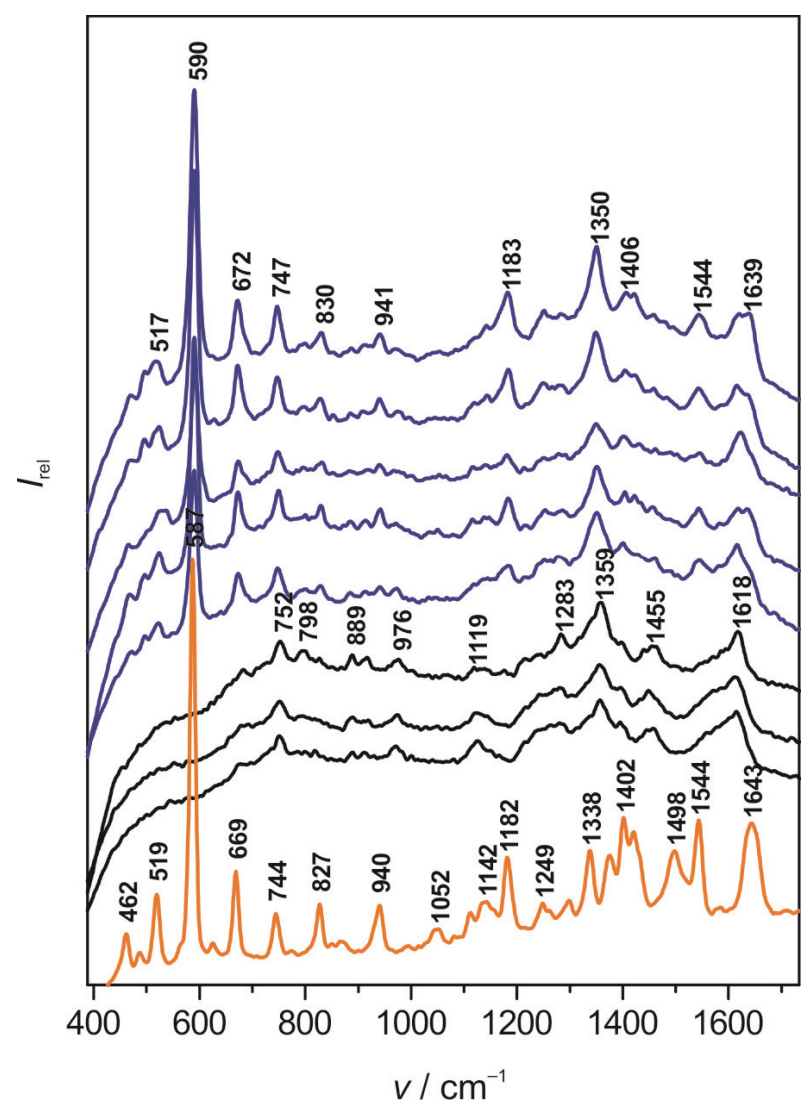

Figure 9. Typical raw SERS spectra collected from various points of the melanoma skin tissue inoculated with $20 \mu \mathrm{l}$ solution $9 \times 10^{-5} \mathrm{~mol} \mathrm{~L}^{-1}$ of $\mathrm{CV}-\mathrm{Ag}$ SERS label (top group) in comparison to SERS spectra of unlabeled nanoparticles. Bottom spectrum showed the pure SERS signal of the tag.

croscopic images succession from the Figure 8, from normal (A), to malignant (D), and described in the experimental section.

Figure 9 presents a series of typical SERS spectra measured from skin of melanoma induced in animal specimens respectively, 2 hours after the subcutaneous injection with $\mathrm{CV}-\mathrm{Ag}$ SERS labels. Unlabeled nanoparticles have been also employed, to explore the CV effect on the SERS skin signal. The spectra clearly showed the possibility to unambiguously detect the SERS tag together with the spectral information from tissue within a highly localized manner. The band at $590 \mathrm{~cm}^{-1}$ was unambiguously identified as CV SERS tag. Attempts to measure FT-micro-Raman spectra from normal skin and melanoma regions failed because of the extremely poor scattering efficiency.

The distinct signal directly observed in the raw spectra shows great promise in applying SERS for tissue monitoring and biomedical diagnostic. The amino functionalized-NPs find growing interest as functional materials for designing biosensor systems, nanocircuitry and biomolecule-templated nanoscale devices. We used the amino-functionalized Ag nanoparticles to survey changes occuring in the tissue components, particularly in the amide I band of proteins, as a representative Raman band for tissue characterization. In order to understand the vibrational behaviour of the amine-functionalized nanoparticles as SERS reporters in complex biomedia, we needed to understand the vibrational properties of such SERS conjugate systems, as presented in this study. Such SERS reporters buried in animal tissue have been very recently highlighted as efficient optical sensors in providing information on molecular conformational changes along malignancy, due to their ability to bind with the specific amino terminals to particular molecular components. Since the complete vibrational characterization of them was absent in the field, the present study provides the complete vibrational description of them in a broad range of Raman experimental conditions.

Obviously, experimental optimization studies are required regarding the concentration dependence SERS signal, the penetration depth of the subcutaneous injected Raman label versus laser spot depth, in order to receive quantitative information concerning the chemical changes along malignancy or tissue monitoring upon pharmaceutical therapy. Further experiments combining the instruments capability and the available laser lines for in vivo measurements, using extremely low dye concentrations, are in progress.

\section{CONCLUSION}

Based on the UV-VIS, FT-Raman, SERS and SERRS spectroscopy and on DFT theoretical calculations, a complete vibrational characterization of the cresyl violet attached to Ag colloidal nanoparticles as SERS label has been performed. We investigated the SERS stability of $\mathrm{CV}$-coated Ag nanoparticles by measuring their extinction spectra and SERS signals (both frequency and intensity) under a wide range of experimental conditions including different excitation laser lines, setups, concentrations and different chemically reduced Ag nanoparticles.

Cresyl violet perchlorate as labeling reagent featuring extremely high Raman scattering efficiency, is a very attractive molecular species for signaling and trace detection using surface enhanced resonance Raman spectroscopy techniques. The molecule was detectable based on its molecular fingerprint at $590 \mathrm{~cm}^{-1}$ using Lee Meisel Ag colloidal nanoparticles when excited with 488, 647, 694 or $1064 \mathrm{~nm}$ laser line. The fingerprint mode was preponderantly attributed to skeletal quadrant stretching which presents a strong polarizability component perpendicularly oriented to the skeletal plane. Combining the high sensitivity of the surface-enhanced Raman scattering (SERS) with the resonance Raman (RR) conditions, CV was easily detectable at picomole level, whereas in nonresonant condition for $\mathrm{CV}$, at micromole concentrations. 
A portable Raman equipment provided the detection capability at nanomole concentration level.

Cresyl violet is adsorbed on the Ag nanoparticles through its chromophore group, resulting in double amino functionalized nanoparticles. Such SERS label can be successfully applied in biological research, displaying amino functional groups free for tagging nucleic acids specific functional groups.

In addition, surface-enhanced Raman spectroscopy in the local optical fields of the silver nanoparticles also provides sensitive information on the immediate molecular environment of the label in the tissue and allows investigation of the local native constituents of the skin tissue or cells. This is demonstrated by recording SERS signal of the reporter as well as by displaying specific SERS signal of tissue components. These results open perspectives in nanomedicine and molecular diagnostic.

Acknowledgements. Financial support from the National Agency for Scientific Research, Grant PN II 2284/2008 is highly acknowledged.

\section{REFERENCES}

1. T. Vo-Dinh, F. Yan, and M. B. Wabuyele, J. Raman Spectrosc. 36 (2005) 640-647.

2. X Qian, X. H. Peng, D. O. Ansari, Q. Yin-Goen, G. Z. Chen, D. M. Shin, D. M. Yang, A. N. Young, M. D. Wang, and S. Nie, Nat. Biotechnol. 26 (2008) 83-90.

3. S. Cîntă Pînzaru, L. M. Andronie, I. Domsa, O. Cozar, and S. Astilean, J. Raman Spectrosc. 39 (2008) 331-334.

4. D. I. Ellis and R. Goodacre, Analyst 131 (2006) 875-885.

5. T. Vo-Dinh, L. R. Allain, and D. L. Stokes, J. Raman Spectrosc. 33 (2002) 511-516.

6. O. Lyandres, J. M. Yuen, M. Nilam, C. Shah, R. P.Van Duyne, J. T. Walsh, and M. R. Glucksberg, Diabetes Technol. Ther. 10 (4) (2008) 257-265.

7. R. A. Tripp, R. A. Dluhy, and T. Zhao, Nano Today 3 (2008) 31-35.

8. K. Kneipp, A. S. Haka, H. Kneipp, K. Badizadegan, N. C. Yoshizawa, C. Boone, K. E. Shafer-Peltier, J. T. Motz, R. R. Dasari, and M. S. Feld, Appl. Spectrosc. 56 (2002) 150-154.

9. J-H. Kim, J-S. Kim, H. Choi, S-M Lee, B-H. Jun, K-N.Yu, E. Kuk, Y-K. Kim, D. H. Jeong, M-H. Cho, and Y-S. Lee, Anal. Chem. 78 (2006) 6967-6973.

10. S. Lee, S. Kim, J. Choo, S. Y. Shin, Y. H. Lee, H.Y. Choi, S. Ha, K. Kang, and C. H. Oh, Anal. Chem. 79 (2007) 916-922.

11. P. S. Ghosh, G. Han, B. Erdogan, O. Rosado, S. A. Krovi, and V. M. Rotello, Chem. Biol. Drug Design 70 (1) (2007)13-18.

12. C. M. Goodman, N. S. Chari, G. Han, R. Hong, P. Ghosh, and V. M. Rotello, Chem. Biol. Drug Design 67 (4) (2006) 297-304.

13. S K Ghosh, S. Kundu, M. Mandal, S. Nath, and T. Pal, J. Nanoparticle Res. 5 (2003) 577-587.

14. K. Nithipatikom, M. J. McCoy, S. R. Hawi, K. Nakamoto, F. Adar, and W. B. Campbell, Anal. Biochem. 322 (2003) 198-207.

15. N. Leopold and B. Lendl, J. Phys. Chem. B 107 (2003) 5723-1527.

16. P. C. Lee and D P. J. Meisel, J. Phys. Chem. 86 (1982) 3391-3395.
17. E. Vogel, A. Gbureck, and W. Kiefer, J. Mol. Struct. 550-551 (2000) 177-190

18. S. Cinta Pinzaru and I. Pavel, SERS and Pharmaceuticals, in S. Schlücker (Eds) Surface Enhanced Raman Spectroscopy: Analytical, Biophysical and Life Science Applications, Weinheim, Wiley-VCH Verlag GmbH \& Co. KGaA, 2010, pp. 129-154.

19. Gaussian 03, Revision E.01, M. J. Frisch, G. W. Trucks, H. B. Schlegel, G. E. Scuseria, M. A. Robb, J. R. Cheeseman, J. A. Montgomery, Jr., T. Vreven, K. N. Kudin, J. C. Burant, J. M. Millam, S. S. Iyengar, J. Tomasi, V. Barone, B. Mennucci, M. Cossi, G. Scalmani, N. Rega, G. A. Petersson, H. Nakatsuji, M. Hada, M. Ehara, K. Toyota, R. Fukuda, J. Hasegawa, M. Ishida, T. Nakajima, Y. Honda, O. Kitao, H. Nakai, M. Klene, X. Li, J. E. Knox, H. P. Hratchian, J. B. Cross, V. Bakken, C. Adamo, J. Jaramillo, R. Gomperts, R. E. Stratmann, O. Yazyev, A. J. Austin, R. Cammi, C. Pomelli, J. W. Ochterski, P. Y. Ayala, K. Morokuma, G. A. Voth, P. Salvador, J. J. Dannenberg, V. G. Zakrzewski, S. Dapprich, A. D. Daniels, M. C. Strain, O. Farkas, D. K. Malick, A. D. Rabuck, K. Raghavachari, J. B. Foresman, J. V. Ortiz, Q. Cui, A. G. Baboul, S. Clifford, J. Cioslowski, B. B. Stefanov, G. Liu, A. Liashenko, P. Piskorz, I. Komaromi, R. L. Martin, D. J. Fox, T. Keith, M. A. Al-Laham, C. Y. Peng, A. Nanayakkara, M. Challacombe, P. M. W. Gill, B. Johnson, W. Chen, M. W. Wong, C. Gonzalez, and J. A. Pople, Gaussian, Inc., Wallingford CT, 2004.

20. W. J. Hehre, L. Radom, P. V. R. Schleyer, and J. A. Pople, $A b$ Initio Molecular Orbital Theory, John Wiley \& Sons, New York, 1986, p. 396.

21. A. P. Scott and L. Radom, J. Phys. Chem. 100 (1996) 16502-16513.

22. P. Sinha, S. E. Boesch, C. Gu, R. A. Wheeler, and A. K. Wilson, J. Phys. Chem. 108 (2004) 9213.

23. G. Schaftenaar and J.H. Noordik, J. Comput.-Aided Mol. Design 14 (2000) 123-134.

24. V. Chis, M. Oltean, A. Parnau, V. Micalus, and S. Filip, J. Optoelectron. Adv. Mat. 8 (2006) 1143-1147.

25. M. Moskovits and J. S. Suh, J. Phys. Chem. 88 (1984) 5526-5533.

26. R. M. Jarvis, H. E. Johnson, E. Olembe, A. Panneerselvam, M. A. Malik, M. Afzaal, P. O'Brien, and R. Goodacre, Analyst 133 (2008) 1449-1452.

27. Y. Sun and Y. Xia, Science 298 (2002) 2176-2179.

28. M. Baia, S. Astilean, and T. Iliescu, Raman and SERS Investigations of Pharmaceuticals (Eds), Springer-Verlag Berlin, Heidelberg, 2008.73.

29. P. Hildebrandt and M. Stockburger, J. Phys. Chem. 88 (1984) 5935-5944.

30. P. Hildebrandt and M.Stockburger, J. Raman Spectrosc. 17 (1986) 55-62.

31. V. M. Hallmark and A. Campion, J. Chem. Phys. 84 (1986) 2933-2942.

32. D. Graham, B. J. Mallinder, and W. E. Smith, Biopolym. 57 (2000) 85-91.

33. Y. W. C. Cao, R. Jin, and C. A. Mirkin, Science 297 (2002) 1536-1540.

34. K. Hering, D. Cialla, K. Ackermann, T. Dörfer, R. Möller, H. Schneidewind, R. Mattheis, W. Fritzsche, P. Rösch, and J. Popp, Anal. Bioanal. Chem. 390 (2008) 113-124.

35. A. Pal, T. Pal, D. L. Stokes, and T. Vo-Dinh, Current Sci. 84 (2003) 1342-1346.

36. J. Kneipp, H. Kneipp, A. Rajadurai, R. W. Redmond, and K. Kneipp, J. Raman Spectrosc. 40 (2009) 1-5.

37. S. Cinta Pinzaru, A. Falamas, and C. Dehelean, J. Cell. Mol. Med. 17 (2013) 277-286. 